\title{
Determinantes sociales y salud neoliberal: hacia una gestión individual del malestar social
}

Autores:

Nicolás Fuster Sánchez. Profesor de Castellano, Doctor en Ciencias Sociales y de la Comunicación, Profesor Titular Escuela de Enfermería. Universidad de Valparaíso, Chile. E- Mail: nicolas.fuster@uv.cl

Hugo Sir Retamales. Sociólogo, Magíster en Ciencias Sociales, Académico de la carrera de Sociología de la Universidad Andrés Bello.

Hace ya varias décadas, el sociólogo norteamericano Talcott Parsons señalaba que la forma más efectiva para establecer el control social no guardaba directa relación con una presencia exuberante de aparatos coercitivos, sino más bien, lo fundamental para mantener las pautas culturales (otra forma de decir "el orden social") es su internalización y, por tanto, el autogobierno de los individuos (1). O dicho en los términos kantianos de Parsons: hacer que los individuos desearan ser aquello que debían ser. Para Bourdieu, es esta transformación de la "necesidad en virtud" uno de los elementos más perniciosos de lo que él llama "poder simbólico"(2), es decir, el poder que permite mantener el orden cultural establecido como "orden de los cuerpos". Aunque para Parsons eran la familia y la escuela las instituciones centrales para la mantención del orden social (1), hoy por hoy son los propios agentes los encargados de gestionar sus cuerpos y sus relaciones con el entorno social. En esta dirección, la intervención autoritaria y coercitiva sólo será requerida frente a zonas de desvíos flagrantes que pongan en riesgo el autogobierno de los individuos.

Por otra parte, en sus análisis sobre el neoliberalismo, Foucault dará cuenta de la noción de gubernamentalidad para referirse, en parte, a una forma de gobierno "regulatoria" (3), es decir, a la gestión de zonas delimitadas de "libertad" donde los sujetos puedan hacer y desear todo lo que se debe hacer y desear. Ahora bien, lo anterior no aparecería ante nuestra mirada como algo muy problemático en la medida de que hoy en día proliferan "estilos de vida" y nuevas formas de conducirse y de gestionar los cuerpos. Es en este sentido que para Rose y Miller las actuales formas de gestión de lo social operarían como una suerte de gobierno a distancia, es decir, la articulación no autoritaria de diversas entidades que promueven la "alineación entre la conducta económica, social y personal con los objetivos socio-políticos" (4). Se trata de una forma de gobierno centrada en la gestión de uno mismo que conmina a la manipulación del propio cuerpo, con el objetivo fundamen- 
tal de describirse y entenderse (para uno mismo y para los otros) a través de una forma específica de comprender lo que es la salud. Se buscará, entonces, transitar desde la tradicional oposición normal/patológico hacia formas de "ser" y "hacer" (estilos de vida) que sean legítimas y deseables para los individuos.

En países como el nuestro, el foco de las políticas en el ámbito de la "asistencia social" está puesto en aquella población etiquetada como "vulnerable". Podríamos pensar, entonces, que la intervención se instala en donde peligra el autogobierno, en donde los cuerpos se salen de control, donde está en riesgo la "internalización de pautas de valor", a decir de Parsons. Esta posición de vulnerabilidad contiene en sí misma una paradoja: si bien hace posible la intervenión del estado en el estilo de vida de quienes han sido objetivados de este modo, les conmina, a su vez, a gestionar individualemente la desigualdad estrcutural y las exigencias de la competitividad propias del neoliberalismo. 0 dicho de otra forma, releva los "estilos de vida" en tanto espacio intervenible, pero invisibiliza los determinates de la salud generales e intermedios (globalización, desigualdades de clase, determinanciones de género, entre otros). En esta dirección, se hace necesario pensar la relación entre salud y sociedad más allá de los "determinantes sociales" propuestos por la Organización Mundial de la Salud (5), dada tanto la a-criticidad, inespecificidad y difusividad que adquiere el "entorno social" en esta perspectiva, como también el rasgo biomédico individualizante que regula su incorporación. Tal cuestión es fundamental, ya que se vincula directamente con la posición social de la biomedicina y su vínculo con los requerimientos del estado y del mercado (6). En este sentido, tanto la literatura especializada como la institucionalidad sanitaria reconocen una relativa incapacidad para hacer frente de manera satisfactoria a los nuevos desafíos sanitarios, no tan sólo de los sistemas públicos de salud, sino del enfoque mismo de la biomedicina, ya que quedan en evidencia sus propios límites. Lo que se relaciona directamente con el modo en que el saber biomédico se presenta como una técnica de gestión del malestar, a saber: procesando problemas sociales de manera individual (4). Esto mirada explicaría las propuestas de modificación del modelo biomédico en distintos niveles, desde el desarrollo del enfoque "bio-psico-social", hasta la denominada "medicina integrativa" $(7,8)$.

Por otra parte, se hace complejo adoptar una posición frente a los determinantes sociales propuestos por la OMS sin detenerse, previamente, en las especificidades que le imprimió a nuestro sistema de salud la instalación del neoliberalismo en Chile. En 1979 se da inicio al desmantelamiento de nuestro sistema nacional de salud con la creación de 27 servicios de salud y del Fondo Nacional de Salud (FONASA), generándose de esta manera la descentralización sanitaria en un Sistema Nacional de Servicios de Salud (SNSS). Posteriormente, un decreto traspasa en 1980 los Consultorios Primarios de Salud a los municipios generándose profundas desigualdades en la atención de los usuarios producto de las diferencias económicas inscritas en las estructuras de las municipalidades. Sin embargo, el avance más radical hacia la neoliberalización del sistema de salud se produce con la creación de las Instituciones de Salud Previsional (ISAPRE) en 1981, lo que genera una caída sostenida del financiamiento del sistema público durante los años de la dictadura militar, pasando de un 3,3\% en 1974, a menos de un 2\% en 1990 (9). Recién el año 2008 el porcentaje del PIB reservado a la salud pública alcanza las cifras que tenía en 1974. Sin embargo, aunque el gasto en salud ha aumentado significativamente, incluso por encima de los países de la OCDE (un 7,3\% del PIB), sigue 
aún muy por debajo del promedio de los países de esta institución (9,3\%), registrándose además desde el año 2013 un proceso de desaceleración (10). Este sistema de provisión mixta, fiel a la lógica de un estado subsidiario, ha generado desigualdades significativas entre las prestaciones y una presión sostenida sobre el sistema público, ya que ha tenido que lidiar con recursos cada vez más escasos y con un carácter universal que le obliga a recibir una cantidad significativamente superior de afiliados. Para el año 2011, más del 80\% de los habitantes de Chile se encuentran afiliados o son beneficiarios de FONASA, mientras que solo un $13 \%$ lo es de una ISAPRE (11). El diagnóstico se agrava aún más si consideramos que el sistema privado gasta per cápita, exactamente, el doble que FONASA (9).

Estos números deben contrastarse también con la forma de financiamiento en salud. En la mayoría de los países pertenecientes a la OCDE, el gasto público en este ítem supera el $70 \%$ en promedio, con la excepción de Chile y Estados Unidos. Nuestro país apenas alcanza el $49 \%$ de gasto público, con una fuerte carga a los hogares que financian casi un tercio del costo, frente al promedio de los países de la OCDE que apenas llega al 20\% (11). Esto implica una notoria individualización de la gestión de los problemas de salud y la correlativa liberalización de los mercados, como ya se mencionó. Por otra parte, la cantidad de profesionales de la salud también es notoriamente inferior a los demás países de la organización internacional, ubicando a Chile en el último lugar junto a Turquía en la cantidad de médicos, con 1,7 por cada 1000 habitantes, muy por debajo del 3.3 promedio OCDE en 2012 ( $n$ i siquiera alcanzando el promedio el año 2000 que fue de 2.7). Asimismo, en el caso de las enfermeras Chile alcanza un 4.2 por cada 1000 habitantes el año 2012, frente a un 8.8 promedio de los países miembros de la organización (11). Estas presiones y limitaciones estructurales se traspasan a los profesionales del campo de la salud pública chilena, imponiéndoles un modelo competitivo de mercado que instala la vida como otra mercancía más $(12,13)$.

\section{Referencias bibliográficas}

1. Parsons T. El Sistema Social. Madrid (España): Alianza editorial; 1999. 536p.

2. Bourdieu P. Meditaciones Pascalianas. Barcelona (España): Editorial Anagrama; 1999. 368p.

3. Foucault M. Seguridad, territorio, población. Curso del Collège de France (1977-1978). Madrid (España): Ediciones Akal; 2008. 416p.

4. Miller P, Rose N. Governing the present. Administering Economic, Social and Personal Life. Cambridge (England): Polity Press; 2008. 272p.

5. Comisión de determinantes sociales, organización Mundial de la Salud (OMS) Subsanar las desigualdades en una generación [en línea]. OMS; 2008 [acceso 15 mar 2010]. Disponible en: http://whqlibdoc.who.int/hq/2008/WHO_IER_ CSDH_08.1_spa.pdf?ua

6. Foucault M. La vida de los hombres infames. Buenos Aires (Argentina): Editorial Altamira. 1996. 220p.

7. Arias K La vejez como deterioro, una categoría de opresión social: Resituando a los adultos mayores. Perspectivas. 2007; XII (18): 159-71.

8. Willis E. Introduction: Taking stock of medical dominance. Health Sociol Rev.2006; 15: 421-31.

9. Sepúlveda C. El sistema de salud chileno. Santiago (Chile): Editorial Aún Creemos en los Sueños; 2010.

10. Organización para la Cooperación y el Desarrollo Económicos (OCDE) Estadísticas de la 
OCDE sobre la salud 2014 Chile en comparación. [en línea]. OCDE; 2014 [acceso 22 abr 2017]. Disponible en: http://www.oecd.org/els/health-systems/Briefing-Note-CHILE-2014-in-Spanish.pdf

11. Ministerio de Desarrollo Social de Chile (MDS). Informe de política social 2012. [en línea]. MDS; 2012 [acceso 05 nov 2013]. Disponible en: http://www.ministeriodesarrollosocial.gob.cl/ ipos-2012/media/ipos_2012_pp_94-125.pdf

12. Rose N. Políticas de la vida en sí. Biomedicina, poder y subjetividad en el siglo XXI. Buenos Aires (Argentina): UNIPE Editorial Universitaria; 2012. 548p.

13. Fuster N. El cuerpo como máquina. La medicalización de la fuerza de trabajo en Chile. Santiago (Chile): Ceibo Editores; 2013. 187p. 